\title{
GCU
}

Glasgow Caledonian

University

University for the Common Good

\section{Performance measurement for the strategic management of healthcare estates}

Rodriguez-Labajos, Laura; Thomson, Craig; O'Brien, Geraldine

Published in:

Journal of Facilities Management

DOI:

10.1108/JFM-10-2017-0052

Publication date:

2018

Document Version

Author accepted manuscript

Link to publication in ResearchOnline

Citation for published version (Harvard):

Rodriguez-Labajos, L, Thomson, C \& O'Brien, G 2018, 'Performance measurement for the strategic management of healthcare estates', Journal of Facilities Management, vol. 16, no. 2, pp. 217-232. https://doi.org/10.1108/JFM-10-2017-0052

\section{General rights}

Copyright and moral rights for the publications made accessible in the public portal are retained by the authors and/or other copyright owners and it is a condition of accessing publications that users recognise and abide by the legal requirements associated with these rights.

Take down policy

If you believe that this document breaches copyright please view our takedown policy at https://edshare.gcu.ac.uk/id/eprint/5179 for details of how to contact us. 


\section{Performance measurement for the strategic management of healthcare estates}

\section{Introduction}

The healthcare estate directly contributes to the delivery of high quality healthcare for patients and it is a key enabler to change in the health system with its contribution largely undervalued and untapped (Naylor, 2017). Unfortunately, for senior management in public healthcare organisations the often vast and valuable facility portfolio presents significant challenges for decisions surrounding the long term planning of future options for the estate (i.e. new-build, modernisation, refurbishment or disposal). These decisions need to relate to the changing demand for care, driven by the aging population, epidemiology issues (change in disease pattern) and the potential impact of new technologies that have been taking place over the last forty years and that will continue with increasing impact in the coming decades. Today hospitals are structures whose design and configuration reflects the practice of healthcare and patient requirements often from a bygone era (McKee and Healy, 2000). Therefore, they are neither efficient nor functional when it comes to efficiently addressing the demands of the service now and in the future. At the same time there is an increasingly austere financial climate in many developed countries that results in cuts to public expenditure which in turn has affected budgets within the healthcare sector (Nunes et al., 2015, Stuckler et al., 2011). An increasing need has arisen to adapt the estate to reflect both current and future demands in order to avoid affecting adversely the quality of health offered to patients and its economic viability (Naylor, 2017).

Responding to these challenges is the subject of much debate within academia and amongst practitioners around the nature of the new strategies required to support the long term planning of healthcare estates which deliver quality services in an efficient and effective manner, while being aligned to the organisational business strategy, organisational goals and priorities. In other words, to achieve the best value that can be delivered from the estates. This is the case within National Health Services (NHS) Scotland which has embarked on a journey in which optimising the value of the healthcare estates has been a key priority. To this end, researchers, advisory bodies and consultants have been developing assessment tools such as performance measurement systems to help asset managers to proactively deal with their portfolios through for example Balanced Score Cards with feed-forward loops, the Soft Landings Framework and the Building Asset Performance Framework (BAPF). Performance measurement systems are tools that encompass the processes of establishing goals, developing a metric set, setting targets, collecting, analysing, interpreting and communicating performance information and results within the organisation and its key stakeholders, implementation action plans for each perspective and the inclusion of causeeffect relationships between performance measures and goals (Brudan, 2010; Gimbert et al., 2010). Støre-Valen and Lohne (2016) mentioned that the analysis of performance data can contribute to strategic decision-making concerning future planning and its potential. In addition, a number of studies in the asset property management literature have identified that performance measurement provides a tool for decision making, considering whether or not to make an investment and to assess the appropriateness of facilities to ensure their alignment with the organisation mission, requirements for facility expansion, real estate acquisition and facility's renovation and retrofit (Lavy et al., 2014 a; Cable and Davis, 2005).

One of the main features of a successful performance measurement system is that the Key Performance Indicators (KPIs) derived from the critical success factors are tightly linked to the 
organisation's business objectives. This feature makes measuring facility performance a useful tool for understanding how organisations might be achieving best value (Atkin and Brooks, 2015). In NHS Scotland, measuring estate performance was implemented in 2011 by the Scottish Government with the 'National Asset and Facilities Services Performance Framework'. Since its adoption the Scottish Government has alleged to have a better understanding of the outcome of the capital investments and to be able to identify under-performing NHS estates, thus supporting NHS Boards with an accurate picture of the current situation. Audit Scotland claimed that this is a necessary practice in order to understand the issues and highlight good management practices. The practice of performance measurement is resource consuming and the costs associated with data collection, analysis and maintenance results are substantial. Therefore, a desire exists from Health Facilities Scotland (HFS) to ensure that the current set of measures and data collected is adequate and proportionate. Indeed there is the belief that their performance measurement system may be a key tool to support the achievement of better value from NHS estates in Scotland and this is achieved through the use of performance estates data to inform strategic decisions. But the general question arising as part of this research is: what is the potential for performance measurement to contribute to optimise the value that is delivered from a healthcare estate in the public sector; and if so, to what extent?.

This question builds on previous research conducted by Rodriguez-Labajos et al. (2016) who reviewed the performance attributes of healthcare estates measured by a number of organisations in English speaking countries. The authors identified that the adoption of performance measurement systems for assessing healthcare estates is not a common practice, and is only adopted by a minority of public organisations driven by strong government direction. These include the four NHS regions of the United Kingdom, New Zealand, the United States of America and some regions of Australia. In all these cases the performance measurement approaches have been implemented by governments with centralised public hospital governance; and in the majority, it has been made mandatory as part of their reporting on the respective measures to their operational healthcare units (boards, trusts, territories, etc.). This fact retracts the current contemporary negative connotation that performance measurement has within a neoliberal market context. Specifically, these systems have been adopted by governments within many western countries and promoted as a technology for ensuring governmental control within the public sector and as a means for associating knowledge and power (Le Galès, 2016; Carter et al., 1995; Osborne and Gaebler, 1992). In addition, previous studies in the public management literature found that the benefits for measurement are weak when the measures are mandated instead of voluntarily implemented, having only a symbolic use (Cavalluzzo and Ittner, 2004). It has also been documented that in many cases they are used merely for meeting external reporting requirements rather than for contributing to internal decision making (Taylor, 2009). In a study conducted by Carman and Fredericks (2008) about how non-profit organisations use data, the authors found that not all the non-profit managers viewed performance measurement as a strategic tool. Indeed, one third of the organisations studied indicated that using performance evaluation data was considered as a resource drain and distraction, even a marketing and promotional tool. In the literature it is agreed that every measurement system and data item should be used by managers to document performance and be directly related to the decisionmaking at some level (Moynihan, 2005; Wholey, 1999). In practice, the review of the literature has shown that this is not always the case. Drawing on these findings the research asks the questions: what role does performance measurement play in current practice for the management 
of healthcare estates at the strategic level? Does the information generated through measurement support decisions, or are they tools adopted by governments as a means of control and accountability? Answering these questions is necessary before mapping a way forward to determine the potential for performance measurement to contribute to optimise the value that is delivered from the estate. To accomplish this aim different research methods are combined, including a pan-EU qualitative questionnaire, interviews with international healthcare providers and the case study of NHS Scotland. Reflecting on the findings to these questions, the research articulates an agenda for future research to move forward. This research is part of a wider research collaboration between Health Facilities Scotland and the Built Environment Asset Management (BEAM) Centre which seeks to identify to what extent performance measurement can contribute to improve the value of the healthcare estates and organisation.

\section{Performance measurement for estates management applied at the strategic level}

The strategic role of estate management emerged in the 1980s when the alignment of the real estate function with an organisation's overall strategic plan started to be recognised as the best management practice (Roulac, 1986). This trend gained more prominence in the 1990s (Brackertz and Kenley, 2002), but it has not been until the 2010s that practitioners have began to recognise facilities as a strategic resource and measurable component of organisational planning which is no longer treated as an inert bi-product of delivering services (Støre-Valen et al., 2014; Harris, 2010). Thus, authors have increasingly emphasised the importance for adopting performance measurement practices to assess the effectiveness of the management practices (Lavy et al., 2010), but also to gauge the performance of the property assets aligned to the organisational goal and priorities. For instance, the Office of Government Commerce stated "measuring the efficiency and effectiveness of property assets is a critical component of better asset management and provides opportunities for increased productivity and delivery of savings" (White, 2011, pg. 9). More specifically in healthcare, Støre-Valen et al. (2014) suggested establishing a national centre in Norway to coordinate a strategic process of Facilities Management to set objectives, coordination, benchmarking and development of measurement criteria. Ware et al. (2017) recently reflected on the need for enhancing the strategic role of Facilities Management (FM), observing that such recommendations have in practice remained low in uptake. They argued that a minority of organisations have adopted performance measurements which capture the effectiveness of the facilities performance, with the majority still only capturing the aspects associated with cost efficiency.

What does the strategic level of management involve? Howarth (2006) postulated that the management of property assets at the strategic level consists of two elements: strategic and operational, with performance measurement practices taking place at both levels. The strategic element involves decisions at a senior level on appropriate investment and management of the assets to service delivery requirements. It encompasses activities such as planning in the longer term and considering future options such as new-build, modernisation, refurbishment or disposal of facilities (Støre-Valen et al., 2014). At this stage, performance information is reported at a senior level at regular intervals with a focus on the long term horizon. On the other hand, the operational element focuses on the running of the facilities on a day-to-day basis within the allocated budget set at the strategic level (Jones and White, 2008). Here, measurement focuses at a lower level and is used to inform decisions over the short to medium term time horizon and is 
reported more frequently. The literature on facilities management contains a number of studies worthy of consideration when identifying performance requirements for measurement at the strategic level. For instance Lavy have conducted significant empirical research on healthcare facilities through their service life. Lavy et al. (2010) presented a literature-based list of categorised Key Performance Indicators (KPI's) that covers the assessment of facility performance, breaking down the KPI's into four major categories: financial, physical, functional and survey-based. Later, these authors reduced the list to seven core KPI's for facility's performance assessment, including maintenance efficiency, replacement efficiency, condition index, functional index, indoor/outdoor environmental quality, absenteeism and user perception (Lavy et al., 2014a). Talib et al. (2013) identified eleven areas for assessing the buildings performance distributed among three categories: functionality, impact and quality. While the production of performance information has received considerable attention in the facilities management and performance measurement literature, the actual use of this information has not traditionally been very high on the research agenda. Largely missing from this literature is an exploration of the question: how is the performance information generated through measuring used in practice for informing decisions at the strategic level? The authors believe that answering this question will enable understanding of the real role that measuring performance can play in the arena of estates management. This paper is a starting point for addressing this gap through examining current practice in the use of performance information for estates management in the context of the healthcare sector, taking the case study of NHS Scotland. The literature suggests that more focus should be on investigating and testing performance measurement practices in the public sector to identify how these systems, which are expensive and resource consuming, can be developed and used where the overall benefits exceed any negative potential (LeRoux and Wright, 2010). These authors also indicate that how performance information is used in decisionmaking in the public sector is not well documented, and call for qualitative research based on interviews to establish a deeper and fuller understanding.

\section{Theoretical framework}

Different purposes for measuring performance are found in the literature and in practice. A summary is presented by Lavy et al. (2014a) which includes features such as assessing the performance in relation to the organisation's goals, reviews past and present functioning, compares performance within and among the facilities, establishes strategies for future actions and provides needed direction to management for decision making. A consistent theme within this literature is the assertion that effective performance measurement should be to primarily inform decisions (Lavy et al., 2014a; National Research Council, 2012; Cable and Davis, 2004). Performance data equips managers with information to guide strategic decision making as they provide valuable insights into organisational strengths and weaknesses (LeRoux and Wright, 2010). Specifically, in the area of estates and facilities management it has been stated that performance data supports decision-making surrounding whether or not to make an investment and to assess the appropriateness of the facility towards the overall organisation mission, facility expansion, real estate acquisition, the facility's renovation and retrofit (Lavy et al., 2014b). These observations provide the framework for performance measurement to allow the research to explore both its intended and actual role within NHS Scotland through an exploration of how performance information is used by the NHS boards to inform decisions at the strategic level. 


\section{Research Strategy}

This research is an initiative of Health Facilities Scotland (HFS) who felt it was important to have an embedded researcher as it enables them to learn and reflect on the emerging findings with a view to shaping research which responds to the challenges they face. The research presented is conducted adopting the Constructive Grounded Theory (C-GT) approach outlined by Charmaz (2006) with its claim to permit the co-production of research and to acknowledge the positionality of the researchers whilst retaining emergent principles. This allowed the authors to design and fit methodological strategies to explore what is discovered along the way; hence facilitating how to define and challenge emergent critical questions along the course of the research. Findings (coconstruction) emerged through an active engagement between the literature, policy and practice following an iterative process. Different research strategies were used to answer the questions which arose throughout the course of the research defining the study in two key stages. The first stage consists of a review of the approaches adopted by international healthcare providers. Three methods were used consecutively to answer the questions emerging, including a review of the grey literature, a qualitative pan-European (EU) questionnaire, and five interviews with senior estates representatives of international healthcare providers. The second stage examined current practice in the use of performance measurement systems taking the NHS Scotland as the case study.

\section{Stage 1- The pan-EU questionnaire}

A pan-EU questionnaire was designed and distributed to the main contact person of each of the nineteen organisation members of the European Health Property Network (EuHPN), covering a total of eleven countries, thus widening the sample from a previous study which focused on English speaking countries (Rodriguez-Labajos et al., 2016). The background of the targeted respondents was diverse including individuals who were involved in the health system and healthcare infrastructure development, planners, advisors and chief architects for the estates. The questionnaire's aim was to identify international organisations that have performance measurement systems in place, the performance measured, how the information is used and how the tool is valuable within their organisations. Due to the low response rate for the questionnaire, members of the EuHPN were contacted via email for a further interview via phone. Only five were kind enough to participate, including Norway, Denmark, Spain, Republic of Ireland and a member of the European Investment Bank (Life Sciences and Health). This low response rate was achieved despite the excellent connections provided by HFS who are a recognised body across EU. Two reasons for this are the fact that English language was not prominent across the healthcare bodies, but potentially more important was that performance measurement was not aligned across the EU with a centralised healthcare system, so many did not recognise the value of survey. The findings helped to establish an understanding of the role of performance measurement in the wider international healthcare estates context and actively informed the questions and considerations of NHS Scotland.

\section{Stage 2- The case study of NHS Scotland}

A series of guidance documents produced by the Scottish Government, public and internal reports accessed via HFS were reviewed informing in-depth nineteen interviews with different HFS and NHS Scotland personnel to establish an understanding and explore the findings in order to define 
the questions and identify the relevant sample for the next three stages of interview. The first round of interviewees were conducted with the estates policy advisor and the assistant director (Property and Capital Planning Division) at HFS, followed by a second round involving interview with sixteen senior estate managers representing sixteen NHS boards whose aim was to elicit the purposes and usefulness for measuring performance. Most of the representatives occupied departmental heads positions from different areas including estates, property or similar roles responsible, among others, for dealing with the analysis and reporting of performance information, and participate in the preparation of the annual property asset management strategy. The interviews were conducted via video conference and where possible face to face. In a third round, a sense checking semi-structured face to face interview was conducted with the estates policy advisor lasting one hour to explore the questions which emerged previously. All data collected was analysed using the grounded theory method with support of qualitative analysis software NVivo 10 and the use of post-it notes. The transcripts were initially coded line by line, followed by focused coding where the most significant and frequent codes were selected that made the most analytical sense when categorising the data into categories and concepts. Techniques like memo writing were also used for this research. The analysis also included comments that came across with the findings from previous interviews with the director of health projects at the Department of Health in Northern Ireland, and five head of the estates in Northern Ireland.

\section{Findings}

\section{Performance measurement for the strategic management of healthcare estates}

Analysis without context can be meaningless and so before discussing the status of performance measurement for healthcare estates management it is essential to set the background for hospital governance and healthcare funding. How estates are managed and the strategic and operational planning delivery in public healthcare is closely linked to the type of hospital governance and this varies greatly between countries. The European Union (2012) classified the different healthcare systems according to the responsibility of the authorities in health funding and power in healthrelated legislation, implementation of healthcare services and the ownership and management of healthcare facilities. Although there are differences in the type of governance, the main distinction is centralised and decentralised, with the centralised type of governance differing in that the "authority for policy making, planning and the ownership and management of facilities is transferred to a higher (more central) level of government from a lower (more decentralised) level of government (e.g. from district to state or from state to national authorities)" (Sreeramareddy and Sathyanarayana, 2013 pg.1). In addition, in centralised systems most of the responsibilities lie with the central government even if implementation is at the territorial level through bodies or agencies representing the central administration. As indicated earlier, measuring the performance of healthcare estates was identified as not common practice across English speaking counties. The authors identified that those organisations present similarities in the measures of estate performance such as physical condition, utilisation, functionality, operation cost, backlog maintenance and maintenance cost; but also variations, as some of the measures that are meaningful for some organisations are not for others due to drivers such as government priorities, policies and organisational goals.

Reviewing the findings from this study, a correlation was identified between the healthcare organisations that have adopted this practice and the centralised control (central government, 
region or territory) of the estate management function. The qualitative survey and phone interviews with the EuHPN members confirmed previous findings that this practice have not flourished within this context except for in Norway which is actively discussing the adoption of a national performance measurement system to support strategic management. The replies to the survey were lower than expected with only eight responses. This small sample lacked representation, but together with the responses from the interviews they allowed sufficient understanding of how performance measurement is considered in other EU countries. The main finding was that in many of these organisations, where the estate function is decentralised, performance measurement does not reflect the practice found, and therefore lacks value as a strategic tool. Some of the reasons provided were the lack of requirement from the governments or other official bodies, the autonomy of each hospital to manage their own facility and the fact that each hospital unit has its own budget.

\section{The current status of performance measurement in NHS Scotland}

As previously stated, healthcare systems across the world are governed by different systems. The NHS in the UK consists of four regions (England, Scotland, Wales and Northern Ireland), each of which has its own National Health Service which is managed at the level of constituent region and each are characterised for being centralised and financed from general taxation. The four regions present similarities on how estates are managed, investment and reporting systems, but also differences as each region has its own government and organisational priorities. In NHS Scotland, the Scottish Government's Health and Social Care Directorate is responsible for allocating capital investments but also for setting healthcare policy, providing strategic direction to the NHS boards and overseeing delivery of services, while the boards have more planning, managerial and operational functions. They are required by the Scottish Government to have appropriate governance, accountability and reporting arrangements in place to ensure the efficiency and effectiveness of the planning, operation, management and disposal of the facilities. Thus, the Scottish Government adopted the National Asset and Facilities Services Performance system for the following purposes:

(1) To demonstrate accountability and transparency.

Public healthcare has a strong commitment to showing accountability and transparency to ministers, stakeholders and the public. Although the estate is regarded as a small part of the whole system, in NHS it is considered fundamental to allow understanding of how facilities provide value-for-money and to ensure that public resources are spent efficiently in the working environment. This is pinpointed by the following quotations from stakeholder interviews:

"The estate constitutes a relatively small part of the whole accountability system, but reporting on the estate performance is still regarded as being important". [The director of health projects from Northern Ireland]

"In both, private and public organisations, there is a need for being accountable to their boards. I mean to have some level of robust information to be able to say what the state of their assets is and the need for further investment”. [The estates policy advisor at NHS]

(2) To support decisions on which projects to prioritise. 
In centralised systems such as the NHS Governments, these are the main investors and capital allocations are determined mostly by the development of business cases which are presented by the health bodies. Hence, formal performance measurement systems offer a more consistent approach among the different health bodies which fosters a national approach aiding policy development, review and establishes accountability. This consistency provides governments with a better understanding of the performance of healthcare estates across the country and to inform better decisions on where to prioritise capital investments within the region. According to RichMahadkar (2015) evidence-based informed decisions are becoming increasingly necessary, taking into account that in the UK budgets are becoming constrained and capital allocation is under pressure.

(3) As a tool to be used by the NHS boards to inform decisions over the building life cycle and provide evidence base in the formulation of the estate management strategies.

In the NHS, decisions around the estate are driven by the clinical strategy and how they can contribute to improve the delivery of health services. It is important that decisions are not taken with the primary aim of improving the figures of the estate KPI's. Despite this, according to the policy advisor at NHS the decisions need to be informed by the data that in turn supports the property asset management strategies prepared biannually by each NHS board mandated by government. A key comment of the usefulness of measuring performance within this context is provided below:

"Performance measurement allows an organisation to identify where the pressures are in terms of what needs to be improved in the estate, which can then be used to inform discussions with the clinical departments, which leads to the most effective solution for implementing the organisation's clinical strategy. More cohesive decisions can then be made about where to allocate investments, what facilities to retain, and which to dispose of". [The estates policy advisor at NHS]

\section{The use of performance information in practice}

When participants from the NHS boards were asked to discuss the role that performance measurement plays within their organisations the answers were far from the stated government intentions. The respondents recognised the value of measuring performance for the operational side of estates performance. Nevertheless, when it comes to the consideration of estates performance at the strategic level, the study found that for a few respondents collecting and reporting on the national KPI's was a "tick box exercise". This practice is seen by many as a government requirement for external reporting rather than as a useful tool for internal purposes. This reaction was not unexpected as similar findings were reported in past literature (Carman and Fredericks, 2008). However, the fact that the Scottish Government is putting a lot of effort into improving the quality and accuracy of data, as well as in the implementation of the system (providing the resources, training and guidelines) and promoting the use of the information for decision making at the strategic level across the NHS boards, this led the authors to question the reason that has resulted in this position. Emerging from the analysis were clear categories such as design issues and the limited long term strategic thinking around the estates in many of the NHS boards. These were clear barriers to the use of the performance information, but also other aspects 
such as target setting or benchmarking were seen by many as not valuable as a means for strategic decision making and improving performance.

\section{Design}

The National Asset and Facilities Services Performance Framework adopted by NHS Scotland consists of a combination of twenty outcome KPI's (also referred as measures) (showing in figure I) aligned to the NHS Scotland Quality Strategy's three Quality Ambitions: person centred, safe and effective care.

Figure I: Performance measured by NHS Scotland

When participants from the NHS Boards were asked about the usefulness of the performance information, there was a general agreement that there were many measures which did not satisfy their information needs. When respondents were asked to rank the KPI's, only six out of twenty were considered relevant by most of the users; these included statutory compliance, high risk backlog maintenance cost, physical condition, functional suitability, space utilisation and in a minority of cases, quality of the environment. Indeed, it was observed that it is in these measures where the government is placing more emphasis and resources to improve the quality and consistency of data. The other fourteen KPI's were seen by the users as promoted by the government and used merely for reporting performance to the directors of finance, chief executives and government. Therefore, they were perceived as not being useful for analysis, nor for the operational management of the facilities or for long-term strategic planning. These include the measures for patient satisfaction, some of the property based measures such as age of the estate and, in a minority, the overall backlog maintenance cost; and also the measures with most significant financial impact (operational/daily activity related).

The question to ask is, should a tool focused on the performance of the healthcare estate in line with strategic objectives provide stronger alignment with more operational considerations for those managing the estate? Contradictory arguments surrounding this question can be found in the literature. Boyne (2002) stated that an effective performance measurement system should include efficiency and effectiveness measures. Efficiency is concerned with achieving relatively shortterm results with minimum resources and effectiveness with attaining longer-term organisational objectives. On the other hand, in a more recent study Mitchell et al. (2013) argued that it was important to differentiate between strategic and operational performance measurements as the strategic fit requires a long-term perspective and it is achieved through strategic, not operational performance. Or, should the focus of measurement move from solely thinking about property to how the property contributes to improvements in the service delivery? The Scottish Government claims that policies and strategies are all developed on the patient-centred premise. Therefore, it is important that the estates reflect this prioritisation within the associated KPI's. Aligned to this approach, in principle, KPI's should address the benefits the estate provides to the services rather than focusing on the physical assets themselves.

\section{Limited long strategic thinking during estates planning}

Concerns arose from the respondents about the extent to which performance information is actively used by the directive team within the NHS board in order to make long term decisions, with many describing this as "limited at best". Statements like "data is useful but currently there 
is not a vehicle to reach the board in order for them to make informed decisions" or "we struggle to get the estate performance information at the top table, so it can be considered strategically". Information is communicated, but in the majority of cases the rationale behind how it informs the strategic decisions is not provided, leaving an evidence-based which is not taking place proactively. The estate is still perceived in many NHS boards as a less important strategic resource which they are required to engage, but who fail to realise its potential value; therefore limiting the ability to achieve better clinical outcomes and for the overall benefit of the organisation. An interviewee set out in their view the wider problem of why performance information is not used for strategic decisions:

"A common concern is that the operational issues of providing safe, statutory compliant and functionally operational buildings take up the full attention of estate managers and directors, and there is limited time given to strategic thinking about longer term plans for transforming the estate to support future healthcare service needs". [The estates policy advisor at NHS]

In addition, there is the feeling that the estate is not being recognised within the NHS boards and is very much a secondary consideration. The statement "clinical is always first" was a strong theme within the interviews. A key comment confirming the perceived secondary role which senior estates managers feel the estates and facilities is viewed within the NHS:

"The organisation does not look at the estates and facilities KPI's with the same degree of focus as it does for the waiting time KPI's". [A senior estate manager]

At the moment, the Scottish Government claims that they are currently taking leadership to make things change with regards how the estate is perceived by the organisation, as well as the NHS boards to adopt a more strategic approach aligning the estates to the clinical strategy. However, the lack of reported leadership from the estates departments to make things change was identified as a main issue in the analysis. Figure II shows how the data needs to flow around the organisation in order to make the best use of it. Evidence exists of a lack of communication within some boards leading to a breakdown in data flow and consequential non-alignment of estates and clinical strategies. Despite these findings, this year, due to encouragement from the Scottish Government, improvements have been identified in the long term strategies set by the NHS boards, resulting in better strategic analysis and interpretation of the data but also the communication between estates and their respective directives at the board and the clinical services.

Figure II: Good practice of how data needs to flow across the organisation

\section{Target setting and benchmarking}

The Scottish Government's intention for the adoption of a national performance measurement system was to provide consistency of data across the country. This allows for benchmarking practices, although most of the respondents argued the usefulness of this practice was not fully realised as they feel that they are not comparing "like for like".

"We look at the performance of the other boards, but we do not take any decisions based on that". [A senior estate manger] 
"It gives an indication of how we are doing, but it is not accurate as every board has different models of delivery". [A senior estate manger]

This can be seen in the context of target setting, although in this case the lack of practice is related to the secondary role of the estate in the organisation. This means that investments and management decisions are not taken with a view to improve the figures of the KPI's. Instead, performance improvements are the outcome of decisions not based solely on property performance data but the clinical demands. Therefore, in this context the traditional concept of targets will be not relevant, either for prioritisation, or as a tool for decision making at the strategic level and therefore the role of targets within this context can be debated.

\section{Discussion and Recommendations}

Unfortunately, although the Scottish Government and NHS Scotland have invested heavily in the design, implementation and maintenance of the performance measurement system, it is currently not being utilised to its full capability. It can be asserted from the interviews that performance data is important for estate stakeholders. Performance data itself is considered necessary, with one respondent observing that "data is the communication channel within the organisation" [a senior estate manager]. They are useful for knowledge transfer between those collecting the data and interpreting it, and those who have to make decisions based on the data, with the measurement systems providing a standardisation in the language and metrics. In line with this argument, Jones and Leonard (2009) argued that performance measurement generates organisational knowledge that is owned by the organisation and codified in some way to preserve it, making it accessible for other employees and wider stakeholders. In addition, KPI's reflect the organisation's vision, mission and strategy and are considered to be important for translating strategy and critical success factors into measurable objectives (Parmenter, 2015). However, the analysis revealed that the application of a performance measurement system applied in this context is viewed by many as a tool for the government to guide their investment prioritisation and as a means for showing accountability and transparency, rather than acting as an instrumental tool for the strategic management of the estates by the NHS boards. Authors have argued previously that the importance of measurement lies in the use of the information to support decisions. The interviews revealed that senior estates managers felt that in NHS Scotland more than two thirds of the measures are not seen as adequate as the performance information resulting from this is not regarded as relevant for operational or strategic decisions, and is perceived as measures solely created and used for external reporting purposes to the government.

In the recent literature it is asserted that to seek performance information, which is perceived as simultaneously servicing different purposes (e.g. as a managerial tool and a tool for the purpose of achieving accountability), is self-defeating, losing the effectiveness of the process of measuring (Gao, 2015; Bromberg, 2009). The lack of alignment between what is requested through the KPI's and the information needs observed in this research aligns with the literature where there is strong agreement that if performance information is not used for evaluation or making decisions, then it is arguably the result of a lack of fit between the information provided and the information needs of the user (Taylor, 2007). This statement is true for more than two thirds of the measures considered in this context, with the remainder of the performance measures being considered by the interviewees as important. This perception is important as it shows the potential of these measures to have an influence, although currently many are not used in the 
decision making other than those related to health and safety issues. Consideration of the literature helps to identify different factors behind the limited use of the performance information internally within the context of NHS Scotland, including leadership and agency professionalism (Moynihan \& Ingraham, 2004), organisational culture (Moynihan, 2005) and individual conviction of the benefits for measuring (Taylor, 2011). In the case of NHS Scotland the analysis revealed that the limited use of the information was due to the limited long term strategic thinking around the estate and the role it plays within the organisation with this linked to the recognition of the estate as less important a strategic function. In addition, targets and benchmarking are stated in the literature as practices of performance measurement that support decisions, but in this context their applicability can be debated and requires further research.

Previous studies argued that the implementation of performance measurement systems is linked to both symbolic and instrumental benefits (Modell, 2004; Moynihan, 2005). Taylor (2007) pointed out that the symbolic benefits are the core strength of performance measurement as it helps to promote the government's image of objectivity and rationality and as a means to show their effectiveness and efficiency (Moynihan, 2005). But, is the government really accountable? The answer is no. There is a large concern across the NHS boards about the huge quantity of data that is required and the feeling is that it goes nowhere. This, together with the assertion of having performance measures whose information do not satisfy their needs, nor is it used actively by the directive board team for strategic decision making, can bring negative effects. At first, those who are responsible for populating, updating and reporting the performance data may feel that they are overloaded with extra work that adds little value or benefit to their roles and organisation. This increases the likelihood of getting low quality data that in turn is reported annually to the governments; therefore, reducing the effectiveness of measuring estates performance for the government purposes of accountability and transparency. Indeed, issues regarding quality and data gaps were documented in different NHS boards. These findings are supported by Taylor (2007) who stated that "the KPI's reported to public reporting authorities cannot improve accountability if these authorities do not act on the indicators, particularly when the KPI's fail to meet their performance information needs" (pg. 341). Earlier, Boyne et al. (2002) pointed out that without the availability of the necessary data, accountability will not be achieved. To avoid this issue this research recommends three actions:

Firstly, organisations should have less but more relevant measures that may lead to better quality than many which are not useful. The principle that should be considered in the design and evaluation of the measures is, either, it is a valuable indicator and needs support, or, it is not and should be withdrawn.

Secondly, for performance measurement to be effective, the performance measured should link property to the services rather than focus on financial aspects. Larssen (2011) claimed that hospital buildings only serve the purpose of assisting the healthcare services to be as functional as possible. Given this, the likes of Krumm and de Vries (2003) have called for buildings to be regarded as a strategic resource which supports core business activities to operate in an effective and efficient manner, instead of the dominant perception of it being seen as solely as having a financial impact on the organisation performance in which cost and valuation come together. Thereby, capturing the clinical issues with the estate might improve the role that estates play in the organisation. 
Third, a good system of implementation is fundamental to ensure the quality of the data and its accountability. For the tool to be valuable it must be implemented by people who are well trained and believe in it (Halachmi, 2005). Therefore, if they are government initiatives, then they should provide the means to make the process easier for the users in order to improve the chance of bringing them on-board as this is the case of the Scottish Government. Findings from interviews with the head of the estates from NHS Northern Ireland showed that the lack of implementation efforts reduced the credibility of the system, leading to gaming as it was evidenced in some returns. In response, the government developed guidelines to provide a consistent framework in which to measure the various criteria. The research shows that this is an influencing factor as a means to create a level of trust and confidence across users as they feel that they are assessed under the same rules when investment prioritisation decisions are being taken. This also brings into question to what extent the estates data influences government decisions when they do not put the tools in place to make easier its utilisation to the user; also, how governments see the estate, as a strategic resource or just as an operational asset? This opens the debate as to whether this is the reason why other public organisations have not adopted performance measurement systems, or whether it is more related to the fact that estate governance is managed by small units and therefore there is less need for strategic thinking.

\section{Conclusions}

The importance of performance measurement in estates management has been recognised by many scholars and practitioners. With a focus on healthcare, this study explored the role of performance measurement for the management of healthcare estates at the strategic level. The findings explain in part the observation that performance measurement tools are mostly adopted by governments where the healthcare property competencies are centralised. Although these findings were tied to an international review, this was limited to English speaking organisations due to a lack of engagement with a pan-EU questionnaire due to an apparent language barrier and an important realisation that in decentralised healthcare systems across the EU there was limited application of strategic performance measurement reflective of the estate. The study revealed that in NHS Scotland this system is not used in the majority of the cases for purposes other than for government accountability and in part to support government investment prioritisation. Their use as a tool for informing decisions at the strategic level is limited mainly by the finite value placed on the estate as a strategic resource within some of the NHS boards. This is resulting in data gaps, apathy and an inability from the Scottish Government to influence change within the estate. The main contribution of this study is that it provides three recommendations which can help to bridge this gap for those healthcare organisations whose governments mandate having performance measurement systems in place and for those that are planning similar implementation. These recommendations may be also extended to other sectors. However, as the study was limited to NHS Scotland, more research is required to consider the applicability of the findings in other centralised healthcare systems and importantly decentralised organisations with less demand for informing high level policy focused on strategic objectives. Given this, the next question to ask is whether the role of performance measurement can be enhanced, but also to what extent can it be extended to other organisations where the hospital governance is decentralised. 


\section{References}

Atkin, B. and Brooks, A. (2015), Total facility management (4th ed.), Wiley Blackwell, Chichester, United Kingdom.

Boyne, G., Gould-Williams, J., Law, J. and Walker, R. (2002), "Plans, performance information and accountability: the case of best value", Public Administration, Vol. 80 No.4, pp. 691710.

Brackertz, N. and Kenley, R. (2002), “A service delivery approach to measuring facility performance in local government", Facilities, Vol. 20 No. 3/4, pp.127-135.

Bromberg, D. (2009), "Performance Measurement: A System with a Purpose or a Purposeless System?, Public Performance \& Management Review, Vol. 33 No. 2, pp. 214-221.

Brudan, A. (2010), "Rediscovering performance management: systems, learning and integration", Measuring Business Excellence, Vol. 14 No.1, pp.109-123.

Cable, J.H. and Davis, J.S. (2004), Key performance indicators for federal facilities portfolios: Federal Facilities Council.

Carman, J. G. and Fredericks, K. A. (2008), "Nonprofits and evaluation: Empirical evidence from the field". New Directions for Evaluation, Vol. 119, pp. 51-71.

Carter, N., Day, P. and Klein, R. (1995), "How organisations measure success: The use of performance indicators in government". Psychology Press.

Cavalluzzo, K. and Ittner, C. (2004), "Implementing Performance Measurement Innovations: Evidence from Government." Accounting, Organization and Society, Vol. 29 No. 3, pp. 243-267.

Charmaz, K. (2006), Constructing Grounded Theory, Sage Publications: London.

European Union (2012), "The management of health systems in the EU Member States - The role of local and regional authorities", available at:

http://cor.europa.eu/en/documentation/studies/Documents/health-systems/health-systemsen.pdf (accessed 5 June 2017).

Gao, J. (2015), "Performance measurement and management in the public sector: some lessons from research evidence", Public Administration and Development, Vol.35 No. 2, pp. 8696.

Gimbert, X., Bisbe, J. and Mendoza, X. (2010), "The role of performance measurement systems in strategy formulation processes", Long Range Planning, Vol.43 No.4, pp.477-497.

Halachmi, A. (2005), "Performance measurement: test the water before you dive in”, International Review of Administrative Sciences, Vol. 71 No.2, pp. 255-266.

Harris, D. (2010), Public sector asset management: a brief history. Ramidus Consulting Limited.

Howarth, A. (2006), "Improving asset management in government departments", A report on improving the capability and capacity of managing property assets in central civil government, Office of Government Commerce (OCG), available at:

www.slideshare.net/Jacknickelson/improving-asset-management-in-governmentdepartments (accessed 10 July 2017).

Jones, K. and Leonard, L.N. (2009), "From tacit knowledge to organizational knowledge for successful KM", in Knowledge Management and Organizational Learning, Springer US, pp. 27-39. 
Jones, K. and White, A.D. (2008), RICS Public Sector Asset Management Guidelines, RICS, London.

Krumm, P.J. and de Vries, J. (2003), "Value creation through the management of corporate real estate". Journal of Property Investment \& Finance, Vol.21 No.1, pp.61-72.

Larssen, A.K. (2011), "Bygg og eiendoms betydning for effektiv sykehusdrift (Buildings impact on hospital effectiveness)", $\mathrm{PhD}$ thesis, Norwegian University of Science and Technology (NTNU), Trondheim, in Norwegian.

Lavy, S., Garcia, J.A. and Dixit, M.K. (2010), "Establishment of KPIs for facility performance measurement: review of literature", Facilities, Vol. 28 No. 9/10, pp.440-464.

Lavy, S., Garcia, J.A. and Dixit, M.K. (2014a), "KPIs for facility's performance assessment, Part I: identification and categorisation of core indicators". Facilities, Vol. 32 No. 5/6, pp.256274.

Lavy, S., Garcia, J.A. and Dixit, M.K. (2014b), "KPIs for facility's performance assessment, Part II: identification of variables and deriving expressions for core indicators", Facilities, Vol. 32 No. 5/6, pp.275-294.

Le Galès, P. (2016), "Performance measurement as a policy instrument". Policy Studies, Vol. 37 No. 6, pp. 508-520.

LeRoux, K. and Wright, N.S. (2010),'Does performance measurement improve strategic decision making? Findings from a national survey of nonprofit social service agencies", Nonprofit and Voluntary Sector Quarterly, Vol. 39 No. 4, pp.571-587.

McKee, M. and Healy, J. (2000), "The role of the hospital in a changing environment". Bulletin of the World Health Organization, Vol. 78 No. 6, pp.803-810.

Mitchell, F., Nielsen, L. B., Nørreklit, H. and Nørreklit. L. (2013), "Scoring Strategic Performance: A Pragmatic Constructivist Approach to Strategic Performance Measurement", Journal of Management \& Governance, Vol. 17 No. 1, pp. 5-34.

Modell, S. (2004), "Performance measurement myths in the public sector: a research note", Financial Accountability and Management, Vol. 20 No.1, pp. 39-55.

Moynihan, D. P. and Ingraham, P. (2004), "Integrative leadership in the public sector: A model of performance information use", Administration \& Society, Vol.36, pp. 427-453.

Moynihan, D. P. (2005), "Goal-based learning and the future of performance management", Public Administration Review, Vol.65 No. 2, pp.203-216.

National Research Council (2012), Predicting outcomes from investments in maintenance and repair for federal facilities, National Academies Press.

Naylor, R. (2017), "NHS Property and Estates: Why the estate matters for patients", available at: https://www.gov.uk/government/publications/nhs-property-and-estates-naylor-review (accessed 20 September 2017)

Nunes, S., Rego, G. and Nunes, R. (2015), "The impact of economic recession on health-care and the contribution by nurses to promote individuals' dignity", Nursing inquiry, Vol. 22 No. 4, pp.285-295.

Osborne, D. and Gaebler, T. (1992), "Reinventing government: How the entrepreneurial spirit is transforming government", Reading Mass. Adison Wesley Public Comp.

Parmenter, D. (2015), Key performance indicators: developing, implementing, and using winning $K P I s$ (third ed.), John Wiley \& Sons, United States. 
Rich-Mahadkar, S. (2015), Strategic asset management for improved healthcare infrastructure planning in English NHS Trusts, Doctor of Philosophy, Loughborough University, Loughborough.

Rodriguez-Labajos, L., Thomson, C. and O'Brien, G. (2016), “Exploring the attributes and KPI's adopted by international healthcare providers to measure the performance of their estates at the strategic level", in 32nd Annual ARCOM Conference, 5-7 September 2016, Association of Researchers in Construction Management, Manchester UK, pp. 12131223.

Roulac, S.E. (1986), "Real estate as a strategic resource", Chief Financial Officer International, pp. 317-21.

Sreeramareddy, C.T. and Sathyanarayana, T.N. (2013), "Decentralised versus centralised governance of health services", available at: http://onlinelibrary.wiley.com/doi/10.1002/14651858.CD010830/pdf (accessed 15 July 2017).

Støre-Valen, M., Kathrine Larssen, A. and Bjørberg, S. (2014), "Buildings' impact on effective hospital services: The means of the property management role in Norwegian hospitals", Journal of health organization and management, Vol. 28 No. 3, pp.386-404.

Støre-Valen, M. and Lohne, J. (2016), “Analysis of assessment methodologies suitable for building performance", Facilities, Vol. 34 No. 13/14, pp.726-747.

Stuckler, D., Basu, S., Suhrcke, M., Coutts, A. and McKee, M. (2011), "Effects of the 2008 recession on health: A first look at European data", Lancet, Vol. 378 No. 9786, pp. 124125 .

Talib, Y., Yang, R.J. and Rajagopalan, P. (2013), "Evaluation of building performance for strategic facilities management in healthcare: A case study of a public hospital in Australia", Facilities, Vol. 31 No. 13/14, pp.681-701.

Taylor, J. (2007), "The usefulness of key performance indicators to public accountability authorities in East Asia", Public Administration and Development, Vol. 27 No. 4, pp.341352.

Taylor, J. (2009), "Strengthening the Link between Performance Measurement and Decision Making", Public Administration, Vol. 87 No. 4, pp. 853-871.

Taylor J. (2011), "Factors influencing the use of performance information for decision making in Australian state agencies", Public Administration, Vol. 89 No. 4, pp. 1316-1334.

Ware, J., Harris, R., Bowen, M. and Carder, P. (2017), "Raising the Bar: From Operational Excellence to Strategic Impact in FM", available at: http://www.rics.org/Documents/Raising_the_Bar_3_Full_Report_240317_IC.pdf (accessed 22 May 2017).

White, A.D. (2011), “A review of UK public sector real estate asset management”, Journal of Corporate Real Estate, Vol. 13 No.1, pp.6-15.

Wholey, J. S. (1999), "Performance-based management: Responding to the challenges", Public Performance and Management Review, pp. 288-307. 
Figure I: Performance measured by NHS Scotland

\begin{tabular}{|c|c|c|}
\hline Property based measures (from EAMS) & Measures from Cost Book & Others \\
\hline $\begin{array}{l}\text { - Physical condition; } \\
\text { - Statutory compliance status of property asset base; } \\
\text { - Backlog maintenance expenditure requirement; } \\
\text { - Significant and high risk backlog maintenance as } \\
\text { percentage of total backlog expenditure } \\
\text { requirement; } \\
\text { - Estate functional suitability; } \\
\text { - Space utilisation; } \\
\text { - Quality of physical environment; } \\
\text { - Percentage of properties less than } 50 \text { years old }\end{array}$ & $\begin{array}{l}\text { - Building area; } \\
\text { - Property maintenance costs; } \\
\text { - Facilities management costs; } \\
\text { - Cleaning cost; } \\
\text { - Energy cost; } \\
\text { - Rates costs; } \\
\text { - Catering costs; } \\
\text { - Portering costs; } \\
\text { - Laundry \& linen cost; } \\
\text { - Waste cost }\end{array}$ & $\begin{array}{l}\text { - PAMS reflective of service needs } \\
\text { and patient preferences; } \\
\text { - Patient opinion of healthcare } \\
\text { accommodation }\end{array}$ \\
\hline
\end{tabular}

Figure II: Good practice of how data needs to flow across the organisation

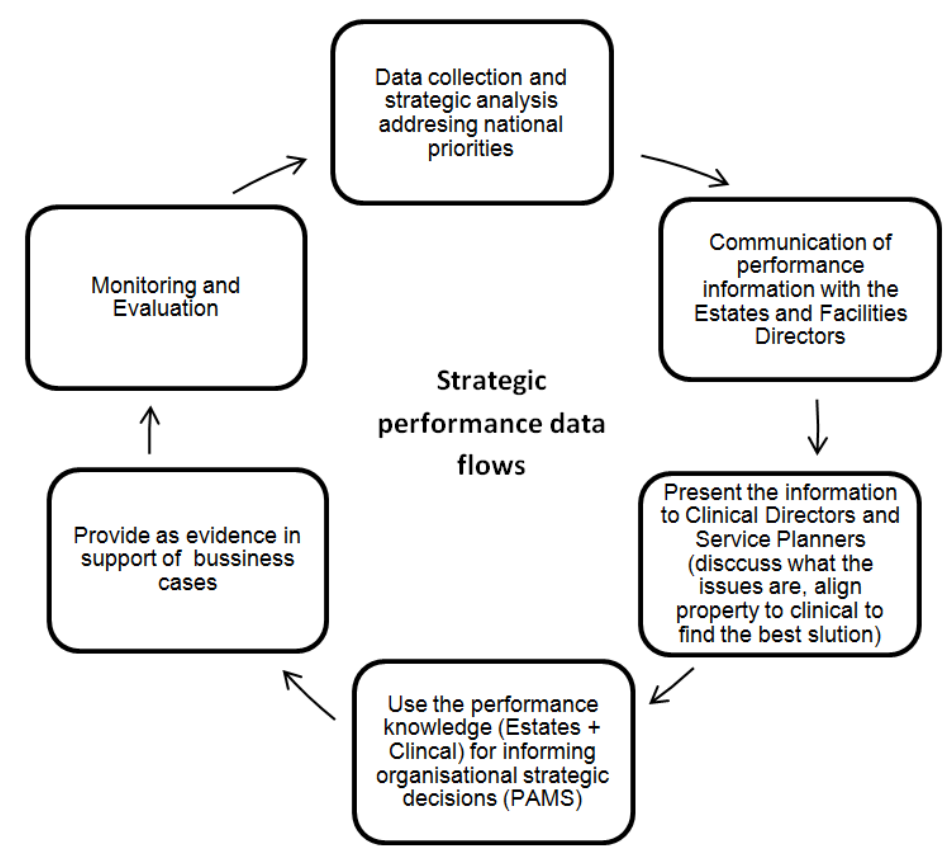

